Rev. Latinoam. Psicopat. Fund., São Paulo, v. 12, n. 1, p. 233-238, março 2009

Christophe Chaperot. "Critique de l'utilisation de l'enseignement de Jacques Lacan dans l'abord psychanalytique des troubles psychotiques ou d'une question postliminaire à tout traitement possible de la psychose" L'Évolution Psychiatrique, v. 73, Issue 4, p. 575-594, Oct.-Dec. 2008.

Vassilis Kapsambelis. "L'eau du bain et le bébé. Sur la conception lacanienne des psychoses" L'Évolution Psychiatrique, v. 73, Issue 4, p. 595-606, Oct.-Dec. 2008.

Eléonore Pardo, Christian Hoffmann. "Remarques sur la théorie lacanienne des psychoses"

L'Évolution Psychiatrique, v. 73, Issue 4, p. 607-614, Oct.-Dec. 2008.

\title{
"Não fica louco quem quer"
}

Guilherme Gutman

Em "Formulações sobre a causalidade psíquica", de 1946, Lacan diz: "É realmente verdade que, como escrevêramos numa fórmula lapidar na parede de nossa sala de plantão, 'Não fica louco quem quer'” (1998, p. 177). Esta frase, que Lacan julga ser grave, ou precisa o suficiente para residir em uma lápide, é desconcertante por algumas razões. Em primeiro lugar, porque podemos imaginar que na parede da sala de plantão não havia apenas "fórmulas lapidares", mas provavelmente mais escatologia do que sabedoria. Segundo, porque nas salas de plantão que conhecemos - ao lado de imãs de geladeira, avisos empoeirados e as escalas de trabalho do mês - não costumamos encontrar qualquer formulação que ultrapasse o senso comum ou algumas gastas formulações de autoajuda. Terceiro, porque na frase referida por Lacan, está presente, de fato, uma concepção daquilo que faz de um louco, um louco. 
Esta mesma frase, rememorada nesse texto que é anterior ao Seminário 3 As psicoses (1955-1956) e a "De uma questão preliminar a todo tratamento possível da psicose" - marcos fundamentais da primeira fase de formulações lacanianas sobre as psicoses - indica que a loucura é uma possibilidade estruturada cedo. Além disso, ela ensina que diante de um determinado evento de vida - um evento, digamos, enlouquecedor - nem todos enlouquecerão, mas apenas aqueles que já possuam uma "estrutura psicótica". Até aqui, a psicanálise lacaniana parece acrescentar pouco à mais rotineira formulação de causalidades, já que mesmo no modelo etiológico de uma psiquiatria main stream, está colocada a ideia de que nas psicoses em geral, e na esquizofrenia em particular, há uma espécie de predisposição (genética?) que, ao encontrar um estresse específico, revela-se no desencadeamento do surto que, por sua vez, marcaria o "ponto zero" sintomático do transtorno em questão.

Assim sendo, qual a contribuição que a psicanálise - neste caso, a psicanálise de filiação lacaniana - pode dar ao modo psiquiátrico de compreender e de atuar nas psicoses? Em torno desta pergunta, foram produzidos recentemente alguns artigos na L'Évolution Psychiatrique. Resumidamente, o primeiro deles "Critique de l'utilisation de l'enseignement de Jacques Lacan dans l'abord psychanalytique des troubles psychotiques ou d'une question postliminaire à tout traitement possible de la psychose" - procura mostrar a premência de um estilo único para que a transmissão do ensino de Lacan possa acontecer de modo adequado, isto é, de maneira que não apenas o seu conteúdo, mas a experiência que ele implica, possa se dar plenamente. Além disso, busca lançar um alerta em relação aos riscos de, ao se transmitir a psicanálise lacaniana segunda o vocabulário e a lógica psiquiátrica contemporâneos, gerar uma má compreensão, ou um mau uso, do que Lacan disse ou escreveu. Os dois artigos que se seguem, comentam, segundo perspectivas um pouco diferentes, a análise e a posição adotadas pelo autor do primeiro.

\section{O estilo é o homem?}

Na primeira parte de seu artigo, Chaperot discorre de modo convincente sobre os instrumentos utilizados por Lacan para "não apenas produzir um ensino, mas para encarnar um ensino" (p. 579): o recurso à poesia, aos matemas e à topologia; a opção pela não fixidez na composição do conceito de objeto $a$; e, finalmente, os seus seminários, tradução viva de seu modo absolutamente pessoal de transmissão. Sobre os seminários - evento/experiência que enlaça os outros instrumentos - escreve Chaperot: 
É o próprio Jacques Lacan que reitera essa ideia de um colocar-se pessoalmente na cena analítica, evento possível em seu seminário: "O que realmente me cabe acentuar é que, ao se oferecer ao ensino, o discurso psicanalítico leva o psicanalista à posição do psicanalisante, isto é, a não produzir nada que se possa dominar, malgrado a aparência, a não ser a título de sintoma. (...).

Se um saber pudesse nascer do seminário, ele seria, pois mais um "saber do inconsciente", "discurso do outro", que teoria verdadeira. (p. 580-581)

A exposição feita por Chaperot do estilo de Lacan tem tudo para agradar a gregos e a troianos: os psicanalistas reconhecerão nela os principais pilares do modo de transmissão lacaniano, expressos ainda num didatismo agradável; e os psiquiatras, estimulados por esse mesmo didatismo, ficarão curiosos em relação aos hábitos e discursos dessa tribo tão diferente da sua.

A segunda parte do artigo, contudo, provocou algum desacordo entre os seus comentadores, mas na mesma medida em que ofereceu mais material para a discussão. Não que nela Chaperot abandone completamente o seu tom didático. Ao contrário, recorre mais uma vez a alguma sistematização ao organizar a teorização de Lacan em torno das psicoses em três principais momentos. O primeiro desses momentos pode ser localizado em torno do Seminário 3 e do conceito de foraclusão do Nome-do-Pai; o segundo em torno do Seminário 23 e dos conceitos de Sinthoma e de suplência; e o terceiro em torno do texto sobre um romance - na verdade, sobre um personagem - de Marguerite Duras. Em relação a cada um desses momentos, Chaperot procura pontuar os supostos riscos de uma má compreensão (temerosamente seguida de uma aplicação apressada ou desastrosa) de cada um desses momentos na clínica com psicóticos.

Começando com o primeiro momento, escreve Chaperot:

O conceito de foraclusão do Nome-do-Pai comporta uma verdadeira pertinência que todo clínico encontra regularmente em sua clínica. As circunstâncias de um desencadeamento (ou evolução) psicótico, as especificidades da estrutura do discurso tais como as dificuldades relativas à paternidade, os efeitos de convocação simbólica se observam e se escutam. O perigo reside na transformação de um ensino que repousa sobre certas modalidades de transmissão e sobre um contexto de debates psicanalíticos cruciais (...) e uma teoria explicativa de cunho etiopatogênico, promulgando uma concepção constitucional deficitária e pessimista. (p. 589)

Em relação ao segundo momento, ele prossegue:

O "Sinthoma" ou a "suplência" por seu caráter reparador e substitutivo são facilmente conotados de inautenticidade, de artificialidade, ao contrario de um Nome-do-Pai sacralizado e fundador de uma verdadeira religião. Esse perfume de heresia pode levar a que se favoreça uma condescendência benevolente no acompanhamento dos esforços dos pacientes psicóticos. Pode-se regularmente ler e entender a propó- 
sito de tal clínica, que se trata de ajudar o sujeito a "remendar" um delírio ou a montar uma suplência. O tom é seguramente condescendente e o referente psicologizante (e não psicanalítico), a suplência (...) operando no imaginário do mesmo modo que uma "função cognitiva" a ser desenvolvida, tal como as terapias cognitivas ajudariam a desenvolver tal ou qual capacidade.

O conceito de suplência comporta, portanto, essa qualidade de algo inautêntico, de ersatz, de sucedâneo, de função de substituição protética e de qualidade menor. (p.590-591)

E, finalmente, em relação a "Lacan e Marguerite Duras", conclui que ao lado da "solução psicótica" de identificação ao falo (tal qual no tantas vezes mencionado “empuxo à mulher”), haveria também a solução de identificação ao objeto (que muitas vezes equivale a dizer, identificar-se ao resto, ao "dejeto”, ao resíduo), que, por sua vez, e a um certo preço, permitiria ao psicótico uma "localização na estrutura". A esta observação, segue-se outra contraindicação que acompanha o seu uso incorreto ou em doses inadequadas:

Aí, uma ideologia suspeita, de exclusão e de alienação, se encontra potencialmente cultivada e argumentada em termos algo ligeiros de "dejetização", pronta a promover uma fascinação passiva pela confirmação tranquilizadora de uma "teoria" asseguradora de uma diferença "radical" entre si e o outro. (p. 592)

\section{O bebê junto com a água?}

As expressões utilizadas por Chaperot para caracterizar as más leituras e as utilizações clínicas equivocadas do pensamento de Lacan são incisivas: "concepção constitucional deficitária e pessimista", "inautenticidade e artificialidade", "condescendência benevolente", "caráter protético e qualidade menor" e "ideologia excludente".

Mas a quem ele se dirige ao formular as suas críticas?

A primeira impressão é a de que Chaperot escolhe o alvo de suas recriminações entre uma população de analistas selvagens e de psiquiatras que ainda conhecem pouco Lacan, o que faz com que, neste caso, as suas críticas percam parte significativa de sua força. Mas essa não é toda a verdade, especialmente quando pensamos na organização de certos serviços em saúde mental. Nestes, não é de todo raro que fatias de psicanálise se combinem a fatias de psiquiatria, produzindo um bolo indigesto. Naturalmente, nada contra combinações em geral: a riqueza clínica desses serviços muitas vezes reside na heterogeneidade dos técnicos, de suas experiências de vida, de trabalho e de suas referências teóricas. O problema é que quando se toma de modo frouxo e descosturado teorias que pedem rigor e 
contextualização, o resultado fica sempre aquém do esperado ou além do aceitável. Neste ponto, devemos concordar com Chaperot. É o que fazem também os autores dos dois outros artigos que resenhamos. Cada um ao seu modo concorda com a primeira parte, mais expositiva e referente às características únicas do ensino de Lacan, em especial aquele segmento referente às psicoses. Ainda que também se imbuam da tarefa de defender Lacan, quando seria então preciso lembrar que Lacan se defende sozinho. Resta como contribuição mais significativa dos artigos referidos, menos as críticas que formulam a Chaperot e mais as reflexões que esse mesmo texto lhes suscita. Se não, vejamos.

Kapsambelis entende que, se alguma posição "antiga" relativa à exclusão do louco sobrevive na sociedade de hoje, mesmo do lado dos técnicos (sob a forma geral de contratransferência), é porque a população apenas reflete e aplica as reações de psiquiatras e de psicanalistas. Segundo ele, a junção de contratransferência à ideia de que haveria um déficit nas psicoses corresponde à dificuldade em se perceber (ou aceitar) a "destrutividade" presente na esquizofrenia, de modo que "estudar a exclusão dos psicóticos equivale a colocar a questão dos efeitos de sua destrutividade sobre nós" (p. 602).

Como contribuição à ideia de direção de tratamento, esse mesmo autor sugere que, em oposição à terapia com neuróticos (onde, segundo ele, haveria um certo apagamento do agir em favor de um pensar), na clínica com psicóticos é preciso construir um "agir terapêutico" para o qual se deveria contar com a psicanálise. Sobre a teoria das ações terapêuticas - e achamos que aqui o principal mérito de Kapsambelis é o de lembrar que, na clínica das psicoses, uma única referência teórica/prática não é nunca suficiente para dar conta da diversidade e complexidade das situações encontradas na clínica -, diz ele:

Ela ainda não foi construída. De qualquer modo, algumas balizas estão disponíveis, saídas de experiências diversas: a teoria e a prática das instituições, das unidades para pacientes de longa permanência às práticas de recepção em emergência; a abordagem dita "psicodinâmica" de prescrição medicamentosa; o levar em conta em certos pacientes, e não apenas nos psicóticos, a necessidade de uma "presença", donde a qualidade válida do aspecto real da experiência vivida (esse "teste de realidade" do qual fala Freud); o trabalho de grupo que, passando do "fazer" para o "fazer com", se mostra um meio privilegiado de interiorização e de identificação; e depois, ao nível das técnicas terapêuticas, os ensinamentos de uma prática como a do psicodrama, do fato do interesse de um "agir" que se situa sempre em uma cena, combinando assim a imposição de um fazer e a necessidade de sua simbolização. E ainda, os agires terapêuticos que remetem à ética (poderão deixar alguém em perigo?), mas que não são menos demandantes de um trabalho de mentalização por parte do paciente, e por parte do terapeuta. E enfim - embora o inventário esteja longe de ser exaustivo - aquelas que são impostas por terceiros (a instituição, as autoridades, os "terceiros pagantes"). (p 604) 
No outro artigo que se debruça sobre o primeiro texto resenhado, Pardo \& Hoffmann, após uma boa revisão sobre aspectos do desencadeamento das psicoses, formulam algumas críticas à leitura de Lacan operada por Chaperot, em particular o seu tratamento dado àquela que seria a leitura lacaniana do romance de Duras. Todavia, do ponto de vista positivo, não acrescentam tanto. Limitam-se, portanto, a apontar o mau uso de Lacan presente no primeiro artigo que, como vimos, centra as suas forças exatamente na crítica às más leituras do discurso lacaniano.

É preciso notar que nesses três artigos trata-se exatamente daquilo que Lacan nunca esqueceu: de frases ditadas por Freud e escritas lá onde os psiquiatras descansam de sua ciência - nas paredes das salas de plantão. É nesse reduto de intimidade que cada um dos psiquiatras, psicanalistas e psicólogos terá que, digamos, fazer alguma coisa com a frase com qual se depara. Embora sempre seja possível recusar o que os olhos vêem e declinar aquilo que a clínica pressente, recuar diante da psicose equivale a deixar a tarefa pela metade.

Até a próxima edição!

\section{Outras Referências}

Lacan, J. (1955-56). O seminário. Livro 3. As psicoses. Rio de Janeiro: Zahar, 1985. . De uma questão preliminar a todo tratamento possível da psicose. In:

Escritos. Rio de Janeiro: Zahar, 1998. p. 537-590. . Homenagem a Marguerite Duras pelo arrebatamento de Lol V. Stein. In:

Outros Escritos. Rio de Janeiro: Zahar, 2003. p. 198-205. . O seminário. Livro 23. O sinthoma. Rio de Janeiro: Zahar, 2007.

\section{Guilherme Gutman}

Psiquiatra e psicanalista; professor adjunto do Departamento de Psicologia da Pontifícia Universidade Católica do Rio de Janeiro - PUC-Rio (Rio de Janeiro, RJ, Brasil) Rua Visconde de Pirajá, 595/905 - Ipanema

22410-003 Rio de Janeiro, RJ.

Fone: (21) 3026-0064 / 9106-7009

e-mail: guilhermegutman@gmail.com 